\title{
Discussion of the Application of Pragmatic Adaptation Theory in College English Translation Education
}

\author{
Xia Yang \\ Jishou University Zhangjiajie College, ZhangJiaJie, China
}

\begin{abstract}
Keywords: pragmatic adaptation theory; college English; translation education; utilization
Abstract. In China, pragmatic adaptation theory, which plays an important role in college English translation education, is the key factor of students to establish situational context. As the college English teaching constantly goes deeper, pragmatics has been widely used in translation teaching gradually and it also has presented obvious advantage. In the study of context, in terms of grammatical language and social language, English translation teaching is constantly setting forth the diversity pragmatic adaptation theory adopted in college education, and together with the function of language in pragmatics in settled contextual model, the selection and adaption of language is intertwined together. Language is always choosing the suitable way to do presentation, while linguistic adaptation is showing the purpose of teaching and constantly reaching the relevant stage. Teaching staff should make best use of pragmatic adaptation theory to discuss its utilization in college English teaching and realize the role transformation from public way to pragmatic adaptation theory, thus further thoroughly analyzing and studying it. Therefore, this paper discussed the pragmatic adaptation theory according to its application in teaching and provided theoretical reference for the application of pragmatic adaptation theory in college English translation teaching.
\end{abstract}

\section{Introduction}

In terms of the current application situation of pragmatic adaptation theory, this paper analyzed the advantages of the development of pragmatic adaptation theory in depth as well as its problems, and put forward suggestive instruction aiming at different problems from the perspective of readers and experts, which constantly completed the strategic and systematic thinking, helped college students establish pragmatics thinking model and built complete pragmatic adaptation theory model. ${ }^{[1]}$ In this process, teaching department can unceasingly promote the pragmatic teaching ability which can establish a good cultivating direction of college students in college English translation education.

\section{Pragmatic adaptation theory}

Nowadays in China the teaching job of pragmatic adaptation theory is to strengthen the communication of participants and complete the integration constantly at micro and macro level, make both sides know each other well, and think from the perspective of the other side as well as at the defined scene. Student-centered and problem-oriented English translation education makes this job transformed into a kind of social work, which can allow both sides accept the behavior and culture of the other side and complete the personality cultivation and social development without losing self-conscious. Latterly, participants can establish their own pragmatic adaptation model independently, master a complete set of learning and researching period and discuss the advantage of pragmatic adaptation theory in college English translation education ${ }^{[2]}$. Starting from one driven problem, the teaching staff designed a set of complete scientific way of learning environment, which provides a good platform for students, expresses the multifaceted English translation education in the aspect of pragmatic language and social-pragmatic, gives full play to the communicative situation function of the incidental language in pragmatic adaptation theory and makes best use of language to choose and comply with the integrated environment, making students improve their ability effectively in this link. At the same time, in order to make teachers have the awareness of heuristic education, the teaching department should make participants can flexibly use and deeply think the 
continuity and subjectivity of pragmatic adaptation theory and keep its dynamic development process $^{[3]}$.

\section{Relevant information about college English translation teaching}

College English translation teaching. In the college English teaching period, translation education occupies a great position. In this period, on the one hand, students constantly improve their learning ability, on the other hand, they also show the comprehensive quality of contemporary college students. However, it is an embarrassing situation that the current situation of Chinese traditional English translation teaching mode is not satisfactory, along with other reasons, this problem appears constantly, thus the translation team becomes more and more difficult to reach the recognized standard of social media. In order to catch up the tide of our society, college English translation education must break through massification and trivialization and regularly learn the various teaching methods of the most popular PBL mode, which can make students more motivated to learn, establish their learning mode step by step, master a set of complete learning and searching period and cultivate the habit of self-learning [4]. Taking the college English translation teaching for example, "preview before class, review after class and examination" circulation teaching method can highlight the students-centered and teacher-oriented subject consciousness. In the constantly learning period, the education department should make the pragmatic adaptation theory seep into the college English translation teaching constantly, let it being applied to the college contextual model and develop and discover our college English translation education continuously [5].

The current situation and existing problems in college English translation teaching. In the teaching period of traditional college mode, taking the relevant teaching cases for example, many students haven't yet learned the basic skill of translation. What is reflected after class is to do the homework by using translation software optionally. This way students neither finish the task nor cultivate the bad habit of laziness in a long time. The traditional translation education develops in monotonous form and lack contents. The cramming method of teaching which is totally outdated, is not only related with hot-spot topics including the mainstream, but also is not flexible in dealing with articles. Most of the methods have been used many years and many syntax translations are passive which finally leads to the abandon of traditional teaching mode and the replace of pragmatic adaptation theory teaching. Therefore, the reason is that traditional teaching method is not well suited for this new period. Education reform has always upgraded in the aspect of mode because the traditional education praised highly by many people before is not doing well in this era. On the one hand it can't finish the task, on the other hand it will delay the unfolding of the whole teaching activities, so it is not worth the candle [6].

\section{The effective use of pragmatic adaptation theory in college English translation teaching}

Cultivating students' consciousness of communication. Nowadays the current situation of Chinese traditional English translation teaching mode is not satisfactory. Along with other reasons, this problem appears constantly, so the translation team becomes more and more difficult to reach the recognized standard of social media. Aiming at the depressed situation of college traditional mode class, in order to catch up the tide of our society, college English translation education must break through massification and trivialization and regularly learn the various teaching methods of the most popular PBL mode. What's more, teachers should train students' consciousness of communication and put themselves in the mindset of students which will make students think actively, comply with the thinking model of other side, establish their learning model step by step, master a set of complete learning and researching period and cultivate the habit of self-learning. Taking the college English translation teaching for example, teachers should practice the "preview-lecture-review-examination" circulation teaching method [7].

Improving the dynamic translation period. Aiming at the effective utilization of pragmatic adaptation theory in college English, from the perspective of teachers, they should not make 
arrangement mechanically and let them accept communicative behavior passively. What they should do is to improve dynamic translation period flexibly based on respecting regulations and supervise the students constantly. In this way, the students will have a general direction and purpose of learning and the method will be helpful to their latter study. Going round and round, teachers should not only play a supervision role, but also play the role of a guide, leading the students to think problems sufficiently, figuring out the students-centered subjective consciousness and making them create their own ways to solve the problem. Last but not least, in the purpose of emphasizing active-learning, it is important to mobilize students' initiative and enthusiasm and use driven-problem-oriented way to complete heuristic education.

Strengthening the micro communication of each side. Nowadays in China the teaching job of pragmatic adaptation theory is to strengthen the communication of participants and complete the integration constantly at micro and macro level, make both sides know each other well, and think from the perspective of the other side as well as at the defined scene. Student-centered and problem-oriented English translation education makes this job transformed into a kind of social work, which can allow both sides accept the behavior and culture of the other side and complete the personality cultivation and social development without losing self-conscious. Latterly, participants can establish their own pragmatic adaptation model independently, master a complete set of learning and researching period and discuss the advantage of pragmatic adaptation theory in college English translation education. By using various effective teaching methods, it can further enhance the students learning passion. Taking the college English learning for example, this way can foster interest of students in translation, especially in the stage of freshman, which is the case-hardened and critical period. Therefore, problem-oriented, not teaching-oriented contextual model should be established. If teachers always teach the students results rather than the way of solving problems, there are differences between the teaching methods. Thus only the teachers follow the course of time, transform their teaching thought and habits and pay attention to foster students' learning interests, can students learn pragmatic adaptation better.

Discussion of the application of pragmatic adaptation theory in college English translation education. Actually teaching activity is a kind of knowledge. Every teacher should carry on the thorough analysis and researches, establish a series of regular activities, improve dynamic translation period, enhance micro communication between each side, find and innovate problem-oriented teaching methods, adopt various teaching methods to generate passion of learning and build easy and active learning environment for students which realizes the discussion of the application of pragmatic adaptation theory in college English translation education [8]. Under the background of college education reform, teachers should fully exploit the students' potentialities through practical activities, motivate students' emotion, strengthen the cultivation of self-learning ability and pay attention to the effectiveness of teaching. Students should also turn passive language study into active application from themselves as well as complete a set of perfect learning plan of their own. At the same time, teachers should regularly find the various teaching methods of pragmatic adaptation theory which can make students generate learning motivation, establish their learning model step by step and master set of complete learning and researching process. Therefore, pragmatic adaptation theory can be made best use in college English translation education.

\section{Conclusion}

Generally speaking, this paper researched and discovered the current problems of college traditional mode teaching and provided theoretical references for the teaching of pragmatic adaptation theory. Nowadays with the in-depth reform college education, on the one hand, it has made significant progress in college education reform including curriculum provision, on the other hand, it allowed Chinese college education to flourish which improved the excellent developing basis, established complete pragmatic adaptation theory model and complete a series of discussion of the application of pragmatic adaptation theory. Therefore, teachers must adopt effective strategies and methods aiming at the current situation of college traditional teaching mode, constantly cultivate the 
learning passion of students and improve their learning ability in each aspect. Only this way can Chinese education make further progress. Anyway, the teachers should adopt different methods among different students and cultivate their interests, rather than follow the general trend. Every child should grow up in a nice environment and every college student should make use of pragmatic adaptation theory, which can provide theoretical references for college English translation education.

\section{References}

[1] Wu Yue, Chen Wenna. Discussion of the application of language awareness in college English translation education [J]. Examination Weekly, 2012(59):76-77.

[2] Zhang Yun. Discussion of the application of pragmatic theory in college English translation education [J]. Reading, Writing and Caculating: Education and Teaching Research, 2011(30).

[3] Wang Meng. Teaching skills and methods of college English translation teaching from the perspective of pragmatics [J]. Anshan Teachers College Journal, 2014(1):54-56.

[4] Ma Xingyu. Analysis of the application of corpus in college English translation education [J]. Education Science \& Culture Periodical, 2010(35):123-124.

[5] Yan Xiaoyan. Discussion of college English translation teaching based on pragmatics [J]. Shandong business Vocational Technical Institute Journal, 2015(1):63-65.

[6] Xing Jiafeng. Discussion of the application of intertextuality theory in college English translation education [J]. Huaihai Engineering Institute Journal (humanities and social sciences), 2015(3):137-140.

[7] Wei Jian. Discussion of the application of multimodal auxiliary stand teaching method in college English translation education [J]. Education Discovery, 2014(2):33-36.

[8] Li Bona. Research of college English translation teaching by using multimedia technology [J]. Neijiang Science and Technology, 2008, 29(6):170-171. 